\title{
Ghanaian EFL Teachers Working in Asia: Benefits and Implications for English Teachers Working Overseas
}

\author{
Mark Treve ${ }^{1}$ \\ ${ }^{1}$ Walailak University School of Languages and General Education, Thailand \\ Correspondence: Mark Treve, Walailak University School of Languages and General Education, Thailand.
}

Received: May 31, 2020

Accepted: June 28, 2020

Online Published: July 2, 2020

doi: 10.5539/elt.v13n8p1

URL: https://doi.org/10.5539/elt.v13n8p1

\begin{abstract}
The present study explores teachers of English as a foreign language (EFL) in Asia, their attitudes toward teaching English, the roles of teaching the English language, motivations, benefits, implications, and the reason they are highly recognized in non-English speaking countries. The researcher applied the qualitative method through semi-structured interviews with $(\mathrm{n}=4)$ Ghanaian teachers working in three countries in Asia as EFL instructors; their strengths and weaknesses were investigated. The result of semi-structured interviews revealed that Ghanaian teachers' primary role in Asia is to teach English and literacy skills. Moreover, the reasons they chose to work in Asia are higher salaries and better working conditions. Their inability to speak the local language and culture diversity were their weaknesses. Native and Non-native English teachers' preferences, which directly/indirectly affect English teaching, are discussed. The respondents' positive attitude toward English teaching overseas is also investigated and presented. This empirical study revealed the globalization of English in the 21st century.
\end{abstract}

Keywords: English as a foreign language, native speaker ideal, native English speaking teacher, non-native English speaking teacher, Ghanaian

\section{Introduction to the Study}

In the 21st century, the world is becoming more of a "global village," and the English language has become its primary language for communication. Svartvik (1999): "1) cited that more than 70 nations use English as an official language. 2) a ratio of one in five persons in the world have got basic knowledge of the English language; 3) about one billion people study the language, 4) Most of the electronics manuals are in English, and most importantly; it is the dominant language used in media, business, science and technology" (Svartvik in Lundahl, 2009, pp.71-72).

The increasingly use of English for communication fuels the demands for English teachers (Crystal, 2003). Moreover, the increasing numbers of learners do not meet the global demands for native English speaking teachers (NEST). In purely economic terms, the demand for native English speaking teachers is higher than the supply of native English speaking teachers (Bayyurt, 2006). Therefore, non-native English speaking teachers (NNEST) are needed (ibid, 2006). English is perceived as the language of success linked to social mobility, status, and economic security; parents in non-English speaking countries throughout the world admitted that their children must learn English before any other language (ibid, 2002b). Moreover, they spend time and money to find the best' representative' teachers of English for their children. In other words, parents prefer to hire native speakers of a specific variety of English.

Ghana is among one of the countries which are considered as a close 'representative' of the English language. The term 'representative' means that Ghana is not a native English speaking country, but the English language is the country's first medium of instruction in schools and businesses. "Accounts of the history of English in Ghana, specifically, the initial contact between the British and the people of the Gold Coast (as Ghana was called then) in the 16th century and the story of how English emerged as the language of trade, education,

governance, and as a cross-ethnic lingua franca abound (Sey, 1973; Boadi, 1994;

Sackey, 1997; Adjaye, 2005). "Noted that the significant elements of the high English proficiency in Ghana relate to the colonial and missionary language policy, the roles of specific individuals during the colonial

period, and the institutional and governmental postures in the post-colonial period." 
Thus, no doubt, English has become a primary language across schools and institutions in the region.

This study aims to examine what motivates Ghanaian EFL teachers to work overseas, basically in Asia; furthermore, to explore the reasons why native English speaking teachers are highly recognized in non-English speaking countries. Additionally, the four Ghanaian teachers' observations regarding their teaching experiences and their perceptions as foreign instructors of English in Asia will be discussed in greater detail. Also, to investigate why Ghanaian EFL teachers prefer to teach in non-English speaking countries; moreover, the researcher believes that in-depth interviews with four Ghanaian EFL teachers may provide insights regarding the benefits and implications of working overseas as EFL teachers.

This study aims to respond to the following questions:

"What do some Ghanaian EFL teachers working overseas identify as their relative strengths and weaknesses compared to native English teachers?"

\section{Background to the Study}

This portion of the study covers the historical perspective of Ghana as to why English became a medium of instruction across all schools and how the country became one of the leading English speaking societies in West Africa. This section also presents articles and relevant previous studies used in this research. It mentions why Ghanaians often possess excellent English language skills and why many Ghanaian teachers go overseas to work as English teachers. It also shelves a comparison of native and non-native speakers of English abilities and responsibilities in the English classrooms.

\subsection{Native vs. Non-Native English Speaking Teachers}

The Ghanaians working as EFL teachers in non-English speaking countries display both strengths and weaknesses. Arva and Medgyes' (2000), in their study, Native and Non-native Teachers in the Classroom, pointed out the differences between native and non-native English speaking teachers. The study revealed that native English speaking teachers are superior in their capability to use the English language spontaneously and in most communicative situations. On the other hand, non-native English speaking teachers generally have a better knowledge of grammar. Most native English speaking teachers do not encounter grammar until they begin teaching, whereas non-native English speaking teachers are used to learning English with the help of grammar (Arva and Medgyes, 2000).

This re-affirmed Cook's (2007) studies, which revealed that non-native English speaking teachers have an advantage in connecting to learners because non-natives know the second language learning strategies. They are also more flexible in the classrooms than native teachers because they understand what language learners go through."

Still, these two categories of English teachers (NEST, NNEST) differ in terms of language proficiency and teaching behavior (Arva \& Medgyes, 2000). Also, argue that NNEST is equally good as teachers in their unique ways. Medgyes showed this in a research survey in an English Language Teaching Journal (ELT) Symposium. He surveyed all ELT specialists who attended the symposium in London and asked whom they would prefer to hire:

1. A native speaker, even when they are not qualified.

2. A qualified non-native teacher.

3. The native speaker/non-native speaker issue would not be part of the selection criteria.

Interestingly, the results shocked Medgyes, when it was discovered that two-thirds of the sixty respondents chose a qualified non-native teacher, one-third of the respondents chose the irrelevance of the native/non-native speaker issue and no one chose a native speaker.

Comparable to Arva \& Medgyes, Haye's (2009) study shows that non-native English teachers are fluent. However, their more substantial areas of teaching are reading and grammar skills. The recognized strengths of native English teachers are, by contrast, in literature, in cultural aspects and pronunciation of the English language.

Hayes (2009) noted that non-native teachers might not be native English teachers and, non-natives may be natives in terms of situational competence. For instance, the respondents in this research were not native Thai or Japanese, neither Chinese. They were not even native-born English speakers, instead of the best representatives for the English language. However, they had closer knowledge about the English culture than the locals. It implies that non-native English speaking teachers may have similar cultural and ethnic backgrounds as their students and while having second-hand knowledge of the culture of the English speaking countries as well as their own. 


\subsection{Native Speaker}

David Crystal (2003) defines the term native speaker as somebody who acquires the language in a natural setting during childhood. The native speaker has intuitive knowledge about his or her language. The way the native speakers use the language that can be trusted. Jenkins (2000) defines a native speaker as follows:

Native speakers are taught to properly use the language, familiar with grammar and vocabulary used, and acquires the dominance in the rules and forms of the language. Native speaker teachers are assumed to have more advantages in teaching their L1 compared to non-native speaker teachers. (Jenkins, 2000, p. 5)Mossou (2006) provides a more detailed characterization of the native speaker:

1. Primacy in order of acquisition

2. Manner and environment of acquisition

3. Acculturation by growing up in the speech community

4. Phonological, linguistic, and communicative competence

5. Dominance, totals, and comfort of use

6. Ethnicity

7. Nationality/domicile

8. Self-perception of linguistic identity

9. Other-perception of linguistic membership and eligibility

10. Monolingual (Mossou, 2006).

It can be found in Longman Dictionary of Language Teaching and Applied Linguistics, that the native speaker is someone who learns language from childhood. Native speakers are said to use the language fluently, grammatically, and appropriately. However, Ghanaian EFL teachers working overseas can be categorized as native English speaking teachers despite English, not their native language. They have learned the language from their childhood and use the language fluently. This categorization is essential to this study as they play different roles in English teaching classrooms, more other non-native EFL teachers.

\subsection{Attitudes to English}

In globalization, the world today is more interconnected. It opens communication across all cultures and other nationalities. Longhurst (2008) defines the term as a process of intermeshing world economies, politics, and culture into globalization, and ESL/EFL teachers working overseas develop the attitude of reflexivity in the classroom. Longhurst (2008) stated that when one seeks to understand and articulate current experiences with the previous experiences. ESL/EFL teachers negotiate their cultural and previous experiences with the current cultural and relationships experienced in a foreign country.

Another effect of the use of English is the way it affects an individual's identity. Lightbown and Spada (2006) cited that when two or more cultures interact, identities are affected. Each individual's identity changes all the time, and the global spread of English in the world also has a positive impact on the learners and English education. There has been a rapid demand for learning the English language, especially in non-English speaking countries. Countries like Japan, China, Thailand, and Korea hire native English-speaking teachers to teach in their schools. One implication is a shift from traditional approaches to oral communicative abilities to cultural and social awareness (Harmer, 2007).

Furthermore, Word Englishes and variations of international Englishes evolve because of globalization. According to Harmer (2007), Word Englishes were formerly classified as inner, outer, and expanding circles and level now evolved to high proficiency and level low proficiency circle. These terms are defined as follows:

\subsection{Inner, Outer and Expanding Circle vs. Proficiency and Low Proficiency Circle}

The respondents of this research are categorized as 'relatively close' to the native speaker of English. Lundahl (2009) cited the outer circle as groups where English is an official language in the country, even though it is not the mother tongue, such as Ghana and Nigeria. Lundahl (2009) also uses the terms inner circle and expanding circle. Countries like Britain, the United States, Australia, and Canada. Where English is the primary language belong to the inner circle category. Meanwhile, countries belonging to the expanding circle are countries that learn English as a foreign or secondary language. Sweden, Denmark, the Asian continent, and some Middle East countries fall into this category. 
However, Harmer (2007) redefines the categories for the English learners where ethnicity is less critical, and proficiency matters more. The proficiency circle here defines as learners who have sufficient knowledge of the English language and culture, while low proficiency circles have less or have no knowledge of the English language and culture. Harmer also adds that "nobody owns the English language anymore and native speakers and non-native speakers of English are alike" (Harmer, 2007, p.18).

Lipovsky and Mahboob (2010) conducted a discourse analysis of written responses provided by Japanese students enrolled in a study abroad program in the United States. The linguistic competences, literacy skills, and teaching methodologies of NESTs and NNESTs were analyzed. Students did not show any preference for either NESTs or NNESTs but valued a combination of their qualities.

\section{Method}

This study explores how EFL teachers perceive themselves concerning their ethnic background. The study focuses mainly on their experiences as English teachers in a foreign country. So, the qualitative interview is the most suitable approach in this study. This approach is common in most studies, such as the present one. The qualitative interview is both efficient and effective since data are collected qualitatively (Burns, 1999). Through the qualitative interview method, the researcher follows up on data in a specific way. Furthermore, the interview parts identify particular issues regarding the participants.

\subsection{Participants' Background}

This section highlights the educational and working experiences of the respondents, as well as their learning strategies and assessments they used when teaching the English language. The countries where they work use English as a mandatory subject in schools.

The respondents of this research are Four Ghanaians English teachers, all Male. They are between the ages of 35-42 years old, and they all chose to work in different countries within Asia in a non-English speaking country. Their names are withheld to keep the respondents anonymous. Moreover, the countries where they work are mentioned to clarify and avoid confusion about their answers. These countries are Japan, China, and Thailand. They all had teaching experience from Ghana before they decided to work outside the country. What is different with these four individuals are that they have different professional backgrounds and reasons for working overseas. These are their stories:

The first respondent works in Wakayama, Japan, and has taught English fulltime since 2014. He teaches English to 10th and 12th graders in a regular public school. He has a degree in Automotive Engineering, and his teaching experience from Ghana covers the only instructional introduction to workers in a Japanese company.

The second respondent also worked in Japan for just two years. He worked in a private school in a different prefecture, Horikoshi. He taught regular classes in high school with 30 to 35 students and special tutorial classes to learners from 19years of age up to 22 years of age. Special classes constituted 3 to 6 students per class. He is a licensed attorney, and his teaching experience in Ghana covers only the subject of psychology. He chose to work for three years in Japan as an EFL teacher because he wanted to experience Japanese culture.

The third respondent works in China. He is a qualified teacher in English and Mathematics and, he was recruited by the Department of Education (the DepEd) in Beijing to teach applied linguistic.

The fourth and the last respondent for this research work in another Asian country, Thailand. He has taught at a public University in the southern region for three years during the study. He is also a qualified teacher in Ghana before he was recruited to work in Thailand. He lives on the campus where he teaches.

\subsection{The Interview Procedure}

The interview questions were semi-structured, which means that sets of questions were prepared beforehand. Interview questions were divided into three categories: i) Personal background: ii) personal perceptions, and iii) approaches to language learning. The English language was used for the interview questions, both written and oral.

Before the interview began, the four respondents were briefed about the interview questions. They were given the preliminary questions in advance, through email, to know the context of the interview. They were also informed about the objectives of this study, and lastly, they were enlightened about ethics and confidentiality. The participants were anonymous to maintain their confidentiality.

In the interview process, there were no distractions because the informants were interviewed after school hours at a convenient time. Therefore, they experienced no time pressure. All four informants are familiar to the interviewer, so previous relationships were already established from both parties. These are friends from high school in Ghana. We keep constant updates of our lives through social media, so we feel comfortable in speaking 
to each other. That was visible in their mannerisms by showing that they were relaxed, smiled, and looked straight to the camera when they answered the questions. Also, the respondents chose to speak English because they felt comfortable with the language.

The interviewees expressed their views and experiences freely because they relaxed in the comfort of their homes. Questions given were in open-ended format and, this type of format allowed them to develop a flowing conversation. Questions used usually began with how, what, and why.

Moreover, the respondents were selected based on convenience because they were accessible through Skype. Two of the respondents work in Japan, one works in China, and the last one works in Thailand. After the interviews were conducted, the researcher chose to divide the results into themes. As follows:

\section{Results and Analysis}

The results of the interview are presented in categories, namely the description of the schools where the respondents work, English as the foreign language used in the schools, the teaching strategies used and experienced by the respondents, and finally, the benefits and implications of working overseas. The respondents also shared their insights about the native speaker's ideal and perceptions of what an English teacher is. Moreover, the results are used to differentiate and point out the limitations of the previous research.

\subsection{Description of the Schools}

The respondents live and work in Asia. In the interview process, the respondents were asked about their school curriculum. All of the respondents pointed out that English were a mandatory subject in the curriculum. However, English exists at different levels. The second respondent from Japan explained that "English is part of the curriculum in grade schools" (Respondent 2, 2020).

Moreover, the first respondent from Japan answered the question in this way:

A good thing in Japan is that English is not a regular subject except in grade 3, grade 6, and up. It became a mandatory subject in 2011[...], so grades 3 and 6 do not get grades, but they are evaluated through this system called a passport. The kids themselves write their comments, and the teacher will check that. (Respondent 1,2020)

The respondent from China replied that their curriculum is based on the British model. He further explained that their curriculum is under the British Department of Education or DepEd. He added that the British schools are now doing the Kto12 Program, which refers to the mandate that all kids attend Kindergarten.

Meanwhile, the respondent from Thailand answered that "the school has a different system here. Junior high school is three years, and senior high school is another three years," and universities differ from institution to institution. (Respondent 2, 2020). Concerning the curriculum, Thailand's curriculum has similarities to the Ghanaian school curriculum and the Japanese. For instance, Thailand and Ghana are similar because the English language is mandatory on all levels, and English as a subject is graded. Thailand is also comparable to Japan in the learning approach, where English as a subject is delegated to two teachers. The local or native Thai teachers are assigned to do the writing and reading comprehension, while the foreign teachers are assigned to teach speaking and listening.

All three countries have English as a mandatory subject in their curriculum. English as a subject in both Japan and Thailand is introduced to learners in early school years. However, it is different in China because the third respondent works in the British community school and English is used as their first medium of communication in school. Furthermore, these countries mentioned have different school curricula, different approaches to teaching the target language, and different criteria for grading their learners. In Japan, for example, students are not graded in the early years of learning, unlike in China, and Thailand pupils are graded.

\subsection{English as a Foreign Language}

The respondents were asked about the importance of English learning to their students. They all replied that learning the English language is their school's first foreign language of choice. Their school even hires native English-speaking teachers or close native English teachers who speak English fluently to teach in their English classrooms. Their students only practice and learn the language mostly in the English classroom; besides, the first respondent from Japan replied:

We have a class named "International Understanding" [...], and every year the school invites native speakers from other countries [...] it may be Asian, for example, from Singapore, Malaysia, or European countries like British or Irish. No Americans preferred because they are already learning it from the regular English class. (Respondent 1, 2020) 
Inviting native speakers from different countries to the schools is unique and relevant for learning languages and cultural awareness. For instance, in Japan, pupils learn different foreign languages, including English, even in different accents like British RP or Scottish English. Countries like Japan and Thailand mentioned in this study consider American English class as their regular English variant.

The respondents from China observed his students speaking fluent English and said that "kids here can speak English well because they are all trained at home" (Respondent 3, 2020). These are foreign-born children in China. Their parents work in China, and they put their children in a British community school, which adopts the British Educational system and uses English as a medium of communication. That shows that learning the language is based on the educational system in the British. English is not only a subject but as a medium of instruction in school as well.

Meanwhile, the respondent from Thailand noted that foreign teachers like he, teach only listening and speaking skills, whereas the writing and reading part are assigned to the Thai English teachers. Comparable to Japan, learning English in Thailand is compulsory, too. Furthermore, students learn English, mainly in the classroom. Each class assigned two English teachers, one native English-speaking teacher or close to a native English speaker like the respondents, while the other teacher is a local born teacher whose job is to assist the foreign teacher by managing the class.

Mahboob, A., and R. Golden. 2013. Cited that countries like Korea, Japan, and Thailand employ foreign English teachers, preferably from English speaking countries, to teach their students to learn the target language, except in China, where the English language is compulsory in all their subjects. That shows that native speakers of English are highly recognized as compared to non-native speakers of English. Comparable to Arva and Medgyes (2000) and Cook (2007), the respondents stated that native speakers of English have more knowledge of their culture and are more competent phonologically, linguistically, and communicatively.

Also, there are pedagogical challenges and benefits to teaching overseas. Comparable to Cook's (2007) study, the respondents from Thailand and Japan mentioned that they make new friends and a broader cultural awareness of the present country. More importantly, the respondents' knowledge of the local culture and language is insufficient that these are also their shortcomings in communicating with their students and guidance. So, local teachers are assigned to assist foreign teachers in the classroom.

\subsection{Teaching Strategies}

When asked about their approaches in teaching English, the respondents from Japan and Thailand stated that only foreign teachers teach speaking and listening skills. Their responsibilities are very limited in the sense that there is another teacher in the class whose duty is to control the students, and this sometimes seems like an impediment in teaching. The first respondent from Japan said:

There was an agreement between the Education board and the school; so, our priority is to develop an interest in learning English. (Respondent 1, 2020) he also explained how English classes are conducted. He said that the steps taken are:

To drill them with vocabulary, and once the students get used to them, then we apply the target language, incorporate games or work in pairs. (ibid, 2020)

The second respondent from Japan replied that it depends on the student's English level and age. He then described his teaching strategy through individual interaction between his students. "We just talk, read some passages, and then interaction" Respondent 2, 2020). He further mentioned his preference for teaching materials from the American Embassy, where he believes it is better than that of the one provided in school. He prefers to use these materials; it gives more room for creativity.

The respondent from China elaborated on the approaches he uses to assess his students; he said that "I grade them based on summative, essay writing and oral presentation." (Respondent 3, 2020). Unlike respondents from Japan, who noted that the students are only assessed according to their class performance.

The finding indicates that respondents wanted to establish an interest in teaching English to their students. They teach their learners through vocabulary drills, games, and exercises, reading comprehension, and speaking interaction. These learners were just pre-intermediate, so repetition is essential in learning the target language. Harmer (2007) states that imitating the words help the learners' transfer knowledge. When the student relates the function and form, they will have the ability to remember the words or phrases.

Respondents in Japan and Thailand noted that their teaching strategies were limited to speaking and listening. Hayes (2009) and Cook (2007) cited in their study that the local English teachers have better grammar, reading, 
and writing skills because local teachers themselves went through the same process while learning the English language. That means local teachers have procedural knowledge, whereas foreign teachers have declarative knowledge. The respondents knew they have a better knowledge of the English culture while the local English teachers have explicit knowledge about the language.

\subsection{Benefits of Working Overseas}

According to West African, No. 4041 (1995), p. 421. It is estimated that Ghanaians in the USA regularly send \$250-350 million per year, which is the motivation factor for Ghanaians to work overseas. Halfway through the interview, the informants were asked about the benefits of working overseas. Respondent 1 from Wakayama, Japan, mentioned that in Japan, they are not strict. The word strict here refers to the qualification to teach. He further noted that parents request to open an English class for their kids.

In the matter of their role as English teachers, the first respondent from Japan mentioned about their duties as teachers are lighter in Japan and teaching is easy because "you do not talk throughout the whole 45 minutes. If you talk the whole period, the students will never understand you" (Respondent 3, 2020).

Another benefit of Ghanaian working overseas is access to modern equipment. The respondent from China mentioned that each student is provided with an individual laptop, and every classroom has an LCD projector. The second respondent from Japan also mentioned another benefit, which is having a teaching assistant in the classroom. He said that "I have two assistants; they do not entrust everything to me" (Respondent 2, 2020). The word refers to discipline. The first respondent from Japan explained further and said that:

The benefits here in Japan, we are not in-charge of classroom control. The Japanese take care of classroom management. (Respondent 1, 2020)

Concerning salary, the second respondent from Japan said that salary in Japan is twice as salary paid in Ghana. He also mentioned about social contacts:

There are many Ghanaian teachers. That is the main reason why I am here because one of my friends had taught here before. I even have a cousin who owns a private business here. (Respondent 2, 2020)

Lastly, the respondent from Thailand also mentioned wages. He said that they pay more, and the standard of living is shallow. Besides, he "is happy to say that his students like him very much" (Respondent 4, 2020).

The result shows that there are many benefits of working overseas; first, there is no strict requirement of working as an English teacher. Respondents from Japan explained that being a fluent English speaker was sufficient enough One of the respondents got his job because of referrals from the parents of his daughter's classmates; they also organized classes for him to teach. Secondly, teaching roles is lighter, where the respondents focus on speaking and listening communication skills. Local teachers in the schools are were given the task of classroom management. However, this is not the case in China, as the teacher and students are from the same culture. This means there is no language barrier.

The principal motivation for these four respondents to work overseas is the higher wages compared to Ghana. Peil, M.(1995), Ghanaians Abroad. African Affairs, 94,345-367.

The economic problems in Ghana forced the respondents to work overseas. Salary overseas is usually twice as much as the regulated salary in Ghana. Working overseas pays off compare to staying in Ghana. Besides, the teachers in this research are also provided with a housing allowance.

Another benefit of working overseas is access to modern technology. Three out of four respondents mentioned that all classrooms are well equipped with modern technologies. The respondent replied that his school is situated in a rural area, and it is not even accessible to any 4-wheel drive. However, he is with a teaching assistant. Comparable to Japan, they had local teachers that assisted them, too. These local teachers secured an order in the classroom. That helped the respondents to concentrate on their language teaching. Lastly, the benefits of working overseas are gaining a more comprehensive social network. There are many Ghanaian working as English teachers, so; there is universal access to meet new people, cultures, and languages. Furthermore, there are many Ghanaians in the country so, they meet new friends and get help from the fellow Ghanaians when the need arises.

\subsection{Implications of working overseas}

When asked about the implications of working overseas, the language issue came up. The second respondent from Japan said that he often encountered problems with the native language. He tried to find another solution for his students to understand him, "like I use body language to explain" (Respondent 2, 2020). The respondent from Thailand used another approach. He said I imitate some essential Thai words, and if I mispronounced the word or 
spoke the language incorrectly," they laugh at me" (Respondent 4, 2020), which is another strategy to make the class more enthralling.

Meanwhile, the respondent from China has no problems getting his message across to his students and points out that "so far I like it here but, this is my first time working overseas, so I feel homesick" (Respondent 3, 2020).

When asked about cultural differences, the respondent from Thailand answered, "They bring baby powder. They want to be presentable, and they want to be white like the Americans" (Respondent 4, 2020). The respondent from Thailand also added, "They (the Americans) are considered attractive and are paid higher, but nobody knows what they are teaching" (Respondent 4, 2020). The statement attractive here means there are right incentives offered to Americans to work in Thailand.

The results in this research show differences in culture and language. This is in line with Arva and Medgyes' (2000) study that Native English speakers are given better incentives and are paid at a higher rate compared to the local English teachers because of their ethnicity and not for their proficiency in the English language. More often, the respondents are dependent on other local teachers. They sometimes ask for assistance in translating English to the learners' native tongue in their activity instructions. However, these respondent failures to help the learners with their grammar limited their students' learning outcomes. The respondents felt misunderstood because of their lack of knowledge of the local language. Hayes (2007) claims that teachers used strategies that seem appropriate for them, and these four respondents are committed to their teaching, and this serves as a counterbalance to their lack of knowledge.

The respondent in Thailand tried to communicate in the Thai language, and he was laughed at for the wrong pronunciation. Ghanaian teachers in Japan and Thailand solve the language barrier by using body language when they could not explain in words.

\subsubsection{Native Speaker ideal}

During the last part of the interview, the respondents were asked about their perceptions of the Native speaker. Respondent 1 from Japan said that Ghanaian English is neutral "it is very understandable and easy to follow" (Respondent 1, 2020). On the other hand, respondents, two from Japan, answered that "there is no particular accent, but you know Ghanaian, we use the British English" (Respondent 2, 2020).

The respondent from China could not determine which accent is dominant and said: "I think ours is based on the British, but China uses more American" (Respondent 3, 2020). The respondent from Thailand answered that American is the preferred accent and replied that "historically, Thailand was under American colony" (Respondent 4, 2020). Besides, Thailand had never been colonized by any foreign country, but American had a significant influence on trading around the Asian continent.

Respondents had different perceptions of what a native speaker of English is. They could not determine which a dominant alternative of English is, but they all had similar preferences, and that is the American English alternative. The dominance of American English in both culture and media indicates their preferences (Bolton and Bautista, 2004). However, Harmer (2007) stated that the global English language belongs to anyone who speaks the language. This reflection of the respondents mentioned the neutrality of his English accent, which enables his students to understand him clearly, and his pronunciation is more comfortable to follow.

The native speaker's perceptions are conflicting and divide the teachers' identity through their ethnicity. That will give a 'we-they' classification. Lundahl (2009) further classified the countries according to the inner, outer, and developing circle.

\subsubsection{English Teacher Ideal}

Finally, concerning the questions of their personal view of what an ideal teacher is, the second respondent from Japan replied that "a good language teacher can teach the language [...] but what is important to me is that they can express themselves" (Respondent 2, 2020). The first respondent from Japan (Wakayama), was also asked the same questions, and he replied:

A good language teacher is someone who, after class, can hear students keep repeating their songs, chants, and target language that, for me, is an affirmation that they are learning something and that they enjoy what they have learned. (Respondent 1, 2020)

The results indicate that only two respondents had a clear understanding of what a good teacher is. That is to teach the students to learn and enjoy learning the target language. The other two respondents misunderstood the question; therefore, they did not answer. Native speakers of English are assumed to be the best teacher in teaching English because they have the ability of cultural knowledge and are fluent in speaking English. However, the result shows 
comparable to Arva and Medgye's (2000) and Cook's (2007) study show that "non-native English teachers are equally good teachers." "The downside of being native English speaking teachers is the linguistic gap with learners because they lack the local exposure of the local language and culture. However, the local teachers' task is to help their learners with their specific challenges." Moreover, Boyle (1997) adds that cultural affinity with students also favors nonnative speaker teachers in an EFL context.

\section{Discussion and Conclusion}

This research's core objectives were to examine the positive attitudes and experiences of Ghanaian EFL teachers working in a foreign country. The results show that working as an EFL teacher in a foreign country has benefits and limitations. The respondents in question were aware of being better qualified to teach English than local English teachers, but also that they consider themselves in some respect better equipped to teach English than native speakers of English. However, being foreigners in the country they work has limitations in regards to teaching roles and cultural gaps. Chun, S. Y. 2014. EFL Learners' Beliefs About Native and non-Native English-Speaking Teachers. Also, being a Non-Native English speaker is one of the implications for Ghanaian teachers working in Asia. However, Yoshihara (2012), claims that "teachers' teaching beliefs play a critical role in their teaching practices" (p. 41). Studies (Golombek \& Johnson, 2004; Nishino, 2009; Woods, 1996; Yoshihara, 2012) have shown that teachers applied their beliefs about teaching to their classroom practices.

\section{Implications and Suggestions for Further Studies}

Finally, Johnson (1990) cited that good teaching is a creative process that demands the constant injection of new information, new perspectives, and new energy. Better learning depends on excellent teaching. Results indicate that parents and students prefer native English speaking teachers because these countries are ethnically homogenous. Homogenous in the sense that all students in class belong to one ethnic group, so the government encourages the schools to introduce foreign language and culture awareness program. Moreover, the best way to learn is through the native speaker of the language. Comparable to Cook's (2007), who argued that native-speakers have the best knowledge of language and culture.

This practice of giving higher moral values to native English speakers in non-English speaking countries should be considered. Schools should focus more on the proficiency of the ESL/EFL teachers and not on ethnicity. That creates an issue where teachers and students think that there is a significant distinction between native English speakers non-native English speakers in terms of classroom teaching.

Arva and Medgyes (2000), argue that an ideal English teacher should be hired based on their professional skills, not on their language background. No one was born to be a teacher. It is a special education or training that makes good teachers. However, teachers' knowledge of the local language is a plus. It gives an advantage in explaining the grammar and shares the learning experience of the target language with the learners.

In a nutshell, this research explored how some EFL teachers perceive their roles as teachers, their teaching strategies, and their experiences of working overseas. The study confirms that there are many implications and benefits of working overseas. These teachers had experience broaden different cultures which broaden their knowledge of working in overseas. They also acquired economic gained and more extensive social recognition. However, the implication of working overseas is the limitation of their teaching responsibilities and their dependency on the local teachers. These respondents also felt their lack of knowledge of the local language and culture led to poor communication.

Their responsibilities were taught only speaking and listening communication skills, and their school curriculum emphasizes the language and cultural awareness of the target language. The learners and parents had a positive attitude towards learning English and towards them as EFL teachers. Students are motivated to learn by actively participating in in-class activities. However, learning English only happens in the English classroom, so their experiences and knowledge of the English language and culture are limited, or their knowledge of the target is low and limited.

The choice of the method used in this research is appropriate and practical. It managed to gather relevant insights from EFL teachers working overseas. However, the respondents of this research are all Ghanaians and all Male. It would be interesting to conduct a follow up to know the insight from the other sex preference, a respondent who does not have a close relationship to the researcher, and also respondents of other nationalities from the interviewer. It will be interesting to know if there would be significant effects on the results of the insights and experiences of working overseas. Would there be other teaching strategies used to motivate the learners? 


\section{Declarations}

* Conflict of interest statement: The corresponding author clearly states that there is no conflict of interest associated with this study.

* Authors contributions: No other author made any contribution to this manuscript

* Funding: No financial assistance was received from anywhere

* Availability of data and material: Not applicable

* Code availability: Not applicable

\section{References}

Arva V., \& Medgye P. (2000). Native and non-native teachers in the classroom. System, (28), 355-372. https://doi.org/10.1016/S0346-251X(00)00017-8.

Bayyurt, Y. (2006). Non-native English teachers' perspective on culture in English as a foreign language classroom. Teacher Development, 10(2), 233-247. https://doi.org/10.1080/13664530600773366

Boyle, J. (1997). Native-speaker teachers of English in Hong Kong. Language and Education, 11, 163-181.

Braine, G. (1999a). From the periphery to the center: One teacher's journey. https://doi.org/10.1080/09500789708666726

Burns, A. (1999). Collaborative action research for English language teachers. Cambridge: Cambridge University Press.

Chun, S. Y. (2014). EFL Learners' Beliefs About Native and non-Native English-Speaking Teachers: Perceived Strengths, Weaknesses, and Preferences. Journal of Multilingual and Multicultural Development, 35(6): 563-579. https://doi.org/10.1080/01434632.2014.889141

Cook, R. (2009). The effects of a short-term teacher abroad program on teacher's perceptions of themselves and their responsibilities as global educators, All Graduate Theses, and Dissertations. Digital Commons, 375 (1). Retrieved 2013-10-10 from http://digitalcommons.usu.edu/etd/375/.

Crystal, D. (2003). A dictionary of linguistics and phonetics. Oxford, Blackwell Publisher.

Dower, J. W. (2010). Cultures of war: Pearl Harbor / Hiroshima / 9-11 / Iraq /.New York: W. W.Norton.

Giddens, A. (1990). The consequences of modernity. Cambridge: Policy Press.

Harmer, J. (2007). The practice of English language teaching. (4th Ed.). Harlow: Longman.

Jenkins, J. (2000). The phonology of English as an international language. Oxford University Press Jinkinson, B. (2003) BBC News World Edition: Empowering the Philippines' Diaspora. February 13. Retrieved 2013-10-10 from http://news.bbc.co.uk/2/asia-pacific/2725211.stm Johnson, K. \& Johnson, H. (red.) (1998). Encyclopedic dictionary of applied linguistics: a handbook for language teaching. Oxford: Blackwell Publishing.

Kazmer, M., \& Xie, B. (2008). Qualitative interviewing in internet studies: Playing with the media, playing with the method. Information, Communication, \& Society, 11, 257-278. https://doi.org/10.1080/13691180801946333

Lightbown, P., \& Spada, N. (2006). How languages are learned .3rd Ed. Oxford University Press.

Lipovsky, C., \& Mahboob, A. (2010). Appraisal of native and non-native English speaking teachers. In A. Mahboob (Ed.), The NNEST lens: Nonnative English speakers in TESOL (pp. 154-179). Newcastle upon Tyne, England: Cambridge Scholars.

Longhurst, B. (red.) (2008). Introducing cultural studies. (2nd Ed.). Harlow, England:Pearson/Longman.

Lundahl, B. (2009) Engelsk språkdidaktik. Texter, kommunikation, språkutveckling. Lund:Studentlitteratur.

Mahboob, A., \& R. Golden. (2013). Looking for Native Speakers of English: Discrimination in English Language Teaching Job Advertisements. Voices in Asia Journal ,1(1), 72-81.

Moussu, L.M. (2006). Native and nonnative English-speaking as a second language teacher: student attitudes, teacher self-perceptions, and intensive English administrators beliefs and practices. West Lafayette, Indiana.

Nalita, J., \& Busher, H. (2007). Ethical issues in online educational research: protecting privacy, establishing authenticity in email interviewing. International Journal of Research \& Method in Education, 30(1), 101-113. https://doi.org/10.1080/17437270701207868 
Peil,M. (1995). Ghanaians Abroad. African Affairs, 94, 345-367. https://doi.org/10.1093/oxfordjournals.afraf.a098834

Richards, J. C., \& Schmidt, R.C. (2002). Longman dictionary of language teaching and applied linguistics. (3rd ed.) London: Longman. Retrieved 2013-10-29. http://globalnation.inquirer.net.

Seidman, I. (2006). Interviewing as qualitative research: A guide for researchers in education and the social sciences Teachers College Press.

Ubalde, M.J. (2007). RP's best teachers are leaving in droves. GMANews.TV. Retrieved September 14, 2013. http://www.gmanetwork.co

Whose English Is It? - TESL-EJ. http://www.tesl-ej.org/wordpress/issues/volume1/ej01/ej01f1/

Yoshihara, R. (2012). ESL teachers' teaching beliefs and practices: A case study of three teachers in an ESL program. The Journal of Humanities and Sciences (Nihon University), 18, 41-61.

\section{Copyrights}

Copyright for this article is retained by the author(s), with first publication rights granted to the journal.

This is an open-access article distributed under the terms and conditions of the Creative Commons Attribution license (http://creativecommons.org/licenses/by/4.0/). 